Revista de Filosofía

ISSN: 0034-8244

https://dx.doi.org/10.5209/resf.68533

\title{
Nietzsche lector de Derrida: restos de una filosofía por venir
}

\author{
Sebastián Chun ${ }^{1}$
}

Recibido: 27 de marzo de 2020 / Aceptado: 15 de junio de 2020

Resumen. Desde un futuro anterior el pensamiento de la deconstrucción asedia a la filosofía del martillo nietzscheana, ya que nos permite re-escribirla a partir de la nueva perspectiva que inaugura. En este artículo nos proponemos abordar principalmente los trabajos de Nietzsche Sobre verdad y mentira en sentido extramoral y Sobre la utilidad y el perjuicio de la historia para la vida, para analizar el modo en que, en estos textos tempranos, la escritura derridiana reconfigura el entramado filosófico nietzscheano. Palabras clave: perspectivismo; vida; voluntad de poder; historia; deconstrucción.

\section{[en] Nietzsche's Reading of Derrida: Remnants of a Philosophy to come}

\begin{abstract}
The deconstructive thought haunts the Nietzsche's philosophy with a hammer from a future anterior since the first one obliges us re-write the last one with Derrida's new perspective. In this article we will read Nietzsche's On Truth and Lie in an Extra-Moral Sense and On the Use and Abuse of History for Life. We will analyze the way in which Derrida's writing re-configurates Nietzsche's philosophical framework.
\end{abstract}

Keywords: perspectivism; life; will to power; history; deconstruction.

Sumario: 1. Disimulo animal; 2. Historia animal; 3. Deconstrucción animal; 4. Referencias bibliográficas.

Cómo citar: Chun, S. (2021): "Nietzsche lector de Derrida: restos de una filosofía por venir", en Revista de Filosofía 46 (2), 313-332.

\footnotetext{
1 Universidad de Buenos Aires, CONICET

sebaschun@hotmail.com
} 
El hecho es que cada escritor crea a sus precursores. Su labor modifica nuestra concepción del pasado, como ha de modificar el futuro.

J. L. Borges, Kafka y sus precursores

The time is out of joint ${ }^{2}$, sentencia Derrida invocando al espectro de Shakespeare, y mediante esta fórmula anuncia que se han resquebrajado las fronteras que delimitan el pasado, el presente y el futuro entre sí. ¿Por qué hemos perdido la capacidad de distinguir los tres éxtasis temporales? Porque no hay presente vivo que no esté asediado por lo ya acontecido y, sobre todo, por el porvenir. El entramado intencional que relaciona lo ya vivido, la actualidad y lo que vendrá, en su indisociable heterogeneidad, vuelve imposible la postulación de un acceso inmediato a nuestro aquí y ahora. Y este temblor es el mismo que lleva a Borges a afirmar que un escritor como Kafka no solo representa un hito que cambia las letras (y el mundo) que lo sucede, sino que tiene la capacidad de modificar a sus precursores. ${ }^{3}$ La lectura de los textos kafkianos sirve de máquina del tiempo que se lanza indistintamente hacia adelante o hacia atrás en la línea temporal, alterando nuestra perspectiva lanzada sobre ese corpus en constante proceso de re-escritura. En este sentido, entendemos aquí que Derrida nos permite releer el trabajo de Nietzsche desde otra perspectiva, poniendo el acento en la herencia del pensamiento de la deconstrucción en la filosofía del martillo nietzscheana. Por lo tanto, nos proponemos seguir un recorrido que se enfocará principalmente en dos textos tempranos del filósofo alemán, en los cuales se evidencia el encuentro entre los pensamientos de Nietzsche y Derrida, para así dar cuenta de la íntima relación entre estos filósofos por venir. ${ }^{4}$

\section{Disimulo animal}

El comienzo de nuestro recorrido es "intergaláctico", ya que el breve escrito de 1873 titulado Sobre verdad y mentira en sentido extramoral comienza insertándose en esa tradición inaugurada por Kant cuando, también al inicio de su Fundamentación de la metafisica de las costumbres, afirma que "ni en el mundo ni, en general, tampoco fuera del mundo, es posible pensar nada que pueda considerarse como bueno sin restricción, a no ser tan solo una buena voluntad". 5 Recordemos que Kant está intentando fundar una ética racional a partir de la cual obtener las leyes a priori para nuestra conducta, libres de cualquier contenido empírico que funcione como resorte a posteriori para la determinación de nuestra voluntad. Por esto, la apelación al universo, a lo extramundano, a la "generalidad" de los seres racionales, los conocidos y aquellos por venir, tiene que ver con un privilegio absoluto de la subjetividad trascendental, hasta ahora solo expresada en el hombre, pero proyectable sobre cualquier razón, incluso aquella desconocida por nosotros. ${ }^{6}$

\section{Derrida (1993).}

Borges (2005b), pp. 93-95.

4 Declaramos la inmensa deuda con los trabajos de Mónica B. Cragnolini. En particular remitimos aquellos referidos a la relación entre Nietzsche y Derrida en torno a la problemática de la animalidad y compilados en Cragnolini (2016).

5 Kant (1995), p. 21.

6 "Añádase a esto que, a menos de querer negarle al concepto de moralidad toda verdad y toda relación con un objeto posible, no puede ponerse en duda que su ley es de tan extensa significación que tiene vigencia, no solo 
Pero tan solo un año después de la publicación de El nacimiento de la tragedia ${ }^{7}$, escrito que en Ecce Homo se reconocerá como todavía impregnado de Hegel, Wagner y Schopenhauer ${ }^{8}$, el comienzo del breve ensayo nietzscheano se posiciona en las antípodas del gesto kantiano. Nietzsche quiere demoler el imperio del sujeto moderno, reducir la razón y su altanería a mero polvo interestelar, contraer hasta la insignificancia a la humanidad, antes proyectada al infinito por la falsa modestia de subsumirla bajo la generalidad de la razón trascendental.

En algún apartado rincón del universo centelleante, desparramado en innumerables sistemas solares, hubo una vez un astro en el que animales inteligentes (kluge Thiere) inventaron (erfanden) el conocimiento (Erkennen). Fue el minuto más altanero y falaz de la "Historia Universal (Weltgeschichte)": pero, a fin de cuentas, solo un minuto. Tras breves respiraciones de la naturaleza el astro se heló y los animales inteligentes hubieron de perecer. ${ }^{9}$

El hombre es un animal, según la fábula que inventa Nietzsche, que encuentra una herramienta cuya finalidad se reduce a la vida humana: el intelecto (Intellekt). Pero este ardid sombrío, caduco, estéril y arbitrario, debe ser interpretado como lo que es: un instante dentro de la historia del hombre, un momento insignificante para la eternidad del universo, y no la piedra angular sobre la que gira el mundo (Welt). El filósofo, el más soberbio de los hombres, pretende ser el centro de lo real, el exponente de la generalidad universal de la razón, pero no es más que un patético animal cuyo anhelo de grandeza no lo diferencia de la simple mosca (Mücke). Y tampoco se distingue del resto de los animales por el deseo compartido de perseverar en la existencia, aunque el hombre lo hace mediante el intelecto y su fuerza principal: el fingimiento (Verstellung). Al no poseer garras ni colmillos acudirá a un suplemento, el artificio del intelecto, que le permitirá enfrentarse a sus competidores en la lucha por la supervivencia superando la desventaja de no contar con la fuerza como medio de conservación. El efecto general, pero también particular, del intelecto será el engaño (Täuschung), el cual se volverá sobre el hombre mismo y su miserable existencia, haciéndolo valorar el conocimiento por sobre todas las cosas.

Y así Nietzsche nos conduce rápidamente a la tesis de su ensayo, cuando afirma que es inconcebible que "haya podido surgir entre los hombres una inclinación (Trieb) sincera y pura (reinen) hacia la verdad". ${ }^{10}$ Vivimos condenados a la superficie de las cosas, presos de ilusiones y sueños que nos alejan de la verdad. Internados ingenuamente en la caverna platónica o inmunes a la duda cartesiana, somos desterrados de nuestro cuerpo sin que nuestro sentido moral (moralisches Gefühl) haga nada por impedirlo. Y esta ignorancia del hombre sobre el "sí mismo (sich Selbst)" le impide reconocer el suelo del que brota el así llamado instinto de

para los hombres, sino para todos los seres racionales en general [...] Pues ¿con qué derecho podemos tributar un respeto ilimitado a lo que acaso no sea valedero más que en las condiciones contingentes de la Humanidad, y considerarlo como precepto universal para toda naturaleza racional?" Kant (1995), p. 31.

7 Nietzsche (1980c) [trad. Nietzsche (2000)].

8 "Para ser justos con El nacimiento de la tragedia (1872) será necesario olvidar algunas cosas. Ha influido e incluso fascinado por lo que tenía de errado, por su aplicación al wagnerismo [...] desprende un repugnante olor hegeliano, solo en algunas fórmulas está impregnada del amargo perfume cadavérico de Schopenhauer." Nietzsche (1980d), pp. 309-310 [trad. Nietzsche (1998), pp. 75-76].

$9 \quad$ Nietzsche (1980b), p. 875 [trad. Nietzsche (1996), p. 17].

10 Nietzsche (1980b), p. 875 [trad. Nietzsche (1996), p. 19]. 
verdad. Nietzsche sostiene que en un estado natural de las cosas el intelecto solo habría servido para fingir, permitiéndole así al individuo conservarse frente a otros individuos. Pero no por la búsqueda de un juez imparcial ni tampoco porque la razón así se lo impusiera, sino por necesidad (Noth) y hastío (Langeweile), el hombre decide pasar a una vida en sociedad y gregaria. Para ello, debe poner fin a la bellum omnium contra omnes mediante un tratado de paz (Friedensschluss), primer paso hacia el así llamado instinto de verdad.

En este mismo momento se fija lo que a partir de entonces ha de ser "verdad", es decir, se ha inventado una designación (Bezeichnung) de las cosas uniformemente válida y obligatoria, y el poder legislativo (Gesetzgebung) del lenguaje proporciona también las primeras leyes de verdad, pues aquí se origina por primera vez el contraste entre verdad y mentira. ${ }^{11}$

Nietzsche no puede fundar el pasaje del estado de naturaleza a la sociedad política en una racionalidad previa que operaría, con mayor o menor eficacia, en ese origen fabuloso del Estado. ¿Por qué? Precisamente porque eso implicaría presuponer un instinto de verdad, una naturaleza humana racional, que es justamente lo que viene a poner en cuestión el carácter protético del intelecto, artefacto ingeniado por una criatura insignificante pero que la engaña primero a ella misma, insuflándole atributos que la harían destinataria de un lugar central y privilegiado en el orden de la creación. El hombre deja este estado natural de las cosas no solo por necesidad, sino también por aburrimiento, por una sensación de tedio que lo invita a conformar una unidad política. Y el momento en que esta sociedad queda erigida es precisamente cuando acuerda una designación común de las cosas. Este convenio, por la fuerza performativa del lenguaje, se vuelve prescriptivo y normativo, estableciendo una frontera entre la verdad y la mentira que se proyecta, por su misma fuerza de ley, hacia lo real (Wirklich) y lo irreal (Unwirkliche). La ley no prohíbe lo falso, sino la mentira, es decir, el querer hacer pasar lo irreal como si fuera lo real, transgrediendo lo consensuado por esa sociedad emergente. Pero ni siquiera el problema radica en la mentira, sino en las consecuencias perniciosas y hostiles del engaño. El hombre, afirma Nietzsche, busca las consecuencias agradables de la verdad, las que conservan la vida, manteniéndose indiferente ante el conocimiento sin consecuencias e incluso hostil frente a las verdades también hostiles. En otras palabras, lo que persigue el conocimiento son las consecuencias que se consideran favorables o útiles de ciertas designaciones de las cosas, rechazando las designaciones, ya sean adecuadas o no, estériles o perjudiciales para la vida.

Y aquí Nietzsche profundiza su análisis, instante que inaugura el así llamado "giro retórico" 12 , preguntándose ahora por la relación entre las designaciones y las cosas, es decir, el lenguaje y la realidad, reflexión que pone en evidencia el papel fundamental que juega en su pensamiento el olvido (Vergesslichkeit). Solo por nuestra capacidad de olvidar podemos creer que poseemos una "verdad", ya que si no aceptamos que la verdad es una mera tautología, una cáscara vacía, es porque estamos intercambiando ilusiones (Illusionen) por verdades. La palabra es la reproducción (Abbildung) en sonidos de un impulso nervioso, la traducción en imágenes sonoras de un destello

Nietzsche (1980b), p. 875 [trad. Nietzsche (1996), p. 20].

Santiago Guervós (2000). 
eléctrico de nuestro sistema nervioso central. Pero presuponer una causa (Ursache), un origen, una presencia exterior a nosotros que diera a luz ese impulso nervioso es ya hacer un uso falso del principio de razón (Satzes vom Grunde). Clasificamos eso que llamamos lo real desde una perspectiva humana, demasiado humana, pero terminamos creyendo que esa arbitrariedad es la verdad de la "cosa en sí". El creador del lenguaje, afirma Nietzsche, se limita a designar las relaciones entre los hombres y las cosas, valiéndose de metáforas para expresarlas. La primera metáfora es la extrapolación del impulso nervioso en imagen (Bild). La segunda, la conversión de esa imagen en un sonido. Ninguna de las tres instancias mantiene relación alguna con la " $\mathrm{x}$ " de la cosa en sí y los dos saltos metafóricos implican un proceso de traducción entre esferas inconmensurables, traición que dejará siempre un resto, una pérdida irrecuperable para cualquier mediación. Así como el sordo cree alcanzar el sonido mediante una imagen en la arena, nosotros creemos dominar lo real mediante ilusiones infinitamente distantes de la cosa en sí. Es por eso que "todo el material sobre el que, y a partir del cual, trabaja y construye el hombre de la verdad, el investigador, el filósofo, procede, si no de las nubes (Wolkenkukuksheim), en ningún caso de la esencia de las cosas (Wesen der Dinge)." "'3 Ahora bien, uno aquí podría preguntarse por el resto de platonismo inscripto en la noción misma de "metáfora", tropos que implica el traslado (pherein) de un sentido recto más allá (meta), hacia un sentido figurado. La metáfora parece siempre implicar su contraparte: el sentido unívoco que se corresponde con lo real. Pero Nietzsche no cae en las redes de Platón, ya que no existe $u n$ sentido detrás de una huella, sino que se pacta establecer uno de los posibles sentidos figurados, siempre diseminados, como el "verdadero", dando lugar a la diferencia entre metáfora y literalidad. Esta es la metáfora de la metáfora que denuncia Derrida, aquella que permanece excluida del sistema metafórico y que permite configurarlo como tal. ${ }^{14}$ Solo hay metáforas y Nietzsche debe recordarnos esto porque el olvido ya ha hecho su tarea.

A continuación Nietzsche analiza, desde esta perspectiva, cómo se produce el concepto (Begriffe), afirmando el carácter testamentario del lenguaje. Si, como sostiene Blanchot, habla la muerte cuando hablamos ${ }^{15}$, esto se debe a que la palabra se vuelve concepto desde el momento en que se desliga de la "experiencia (Urerlebniss) singular y completamente individualizada a la que debe su origen (Entstehen)"16. El concepto, para ser tal, debe ser iterable, es decir, repetible y asignable a la diferencia. Esta es la condición de posibilidad de la escritura, afirma Derrida, ya que solo en la muerte del destinatario, el autor y el referente una marca puede ser considerada lenguaje. ${ }^{17}$ Abandonamos las condiciones individuales de una experiencia particular, dice Nietzsche, desde el momento en que el lenguaje interviene y aniquila la singularidad de la diferencia para circunscribirla dentro de lo "ya conocido" capturado en el concepto. Pero esa experiencia singular no conduce a un presente vivo, arkhé que todavía nos permitiría soñar con una verdad por correspondencia, ya que esa instancia originaria remite a un impulso nervioso, subjetivo, que interpreta,

\footnotetext{
Nietzsche (1980b), p. 879 [trad. Nietzsche (1996), p. 23].

Derrida (1972c), p. 302.

"Toda palabra es violencia que desde ya se ejerce sobre lo que nombra la palabra y solo puede nombrar retirándole la presencia -señal, lo hemos visto, de que habla la muerte (esta muerte que es poder) cuando hablo-." Blanchot (1970), p. 85.

16 Nietzsche (1980b), p. 879 [trad. Nietzsche (1996), p. 23].

17 Derrida (1972a), pp. 374-376.
} 
traicionando, esa "x que es para nosotros inaccesible e indefinible."18 Incluso la oposición entre individuo y especie es antropomórfica, señala Nietzsche, pero hasta tal punto estamos escindidos de la esencia de las cosas que no podemos ni afirmar ni negar que esa categorización se corresponda con estas, siendo cualquiera de las dos opciones dogmática e indemostrable.

¿Qué es entonces la verdad? Una hueste (Heer) en movimiento de metáforas, metonimias, antropomorfismos, en resumidas cuentas, una suma de relaciones humanas que han sido realzadas, extrapoladas y adornadas poética y retóricamente y que, después de un prolongado uso, un pueblo considera firmes, canónicas y vinculantes (verbindlich); las verdades son ilusiones de las que se ha olvidado que lo son, metáforas que se han vuelto gastadas y sin fuerza sensible, monedas que han perdido su troquelado y no son ahora ya consideradas como monedas, sino como metal. ${ }^{19}$

Nos encontramos con la verdad entendida como un ejército conformado por tropos móviles, contingentes, fugaces, pero que, gracias al olvido, han adquirido fuerza de ley. La virtualidad del valor ahora es considerada pura objetividad o, en palabras de Derrida, hemos olvidado el carácter performativo de toda huella, incluso de aquella que pretende ser un reflejo "fiel" de la realidad. ${ }^{20}$

Por lo tanto, existe en el hombre un compromiso a mentir de la manera convenida socialmente, y del olvido de este pacto nace el sentimiento de verdad. Y del sentimiento de este compromiso, sostiene Nietzsche, se sigue el movimiento moral hacia la verdad. Despreciamos al mentiroso, aquel que utiliza las ilusiones no legitimadas socialmente, lo excluimos de la comunidad y privilegiamos lo honesto y fiable. Por esta razón, rechazamos también lo repentino, lo fugaz, lo inesperado, inclinándonos por las abstracciones, las que nos ofrecen un mundo previsible gracias a la potencia mortífera del concepto. Y una vez que construimos esos esquemas podemos hacer lo que nunca se podría realizar a partir de las impresiones intuitivas: construir un mundo de jerarquías, piramidal, que se contrapone y subyuga al mundo de las metáforas intuitivas individuales. Se necesita salir de la pura diferencia para poder estratificar lo real, pero en ese mismo gesto lo perdemos, ya que solo jerarquizamos conceptos. Respetar este orden conceptual, esta legislación de la razón, será acceder a la verdad. Y así nos olvidamos de la extrapolación artística que se da entre cada esfera, cada paso que media entre el impulso nervioso individual y el concepto. El hombre se vuelve así un genio de la construcción (Baugenie) que crea el propio material con el que levanta ese edificio de cimientos fugaces. Y aquí Nietzsche retoma el diálogo con Kant, cuando ridiculiza el gesto de la razón al vanagloriarse por encontrar eso que ella misma escondió. ${ }^{21}$ Lo que busca el hombre es asimilar el mundo a su propia

\footnotetext{
Nietzsche (1980b), p. 880 [trad. Nietzsche (1996), p. 24].

Nietzsche (1980b), pp. 880-881 [trad. Nietzsche (1996), p. 25].

Derrida (1972a), p. 390.

“[...] se encendió una luz para todos los investigadores de la naturaleza. Comprendieron que la razón solo entiende lo que ella misma produce según su [propio] plan; que ella debe tomar la delantera con principios de sus juicios según leyes constantes, y que debe obligar a la naturaleza a responder a sus preguntas, mas no debe solo dejarse conducir por ella como si fuera llevada del cabestro; pues de otro modo observaciones contingentes, hechas sin ningún plan previamente trazado, no se articulan en una ley necesaria, que es, empero, lo que la razón busca y necesita. La razón, llevando en una mano sus principios, solo según los cuales los fenómenos coincidentes pueden valer como leyes, y en la otra el experimento, que ella ha concebido según aquellos [principios], debe dirigirse a la naturaleza para ser, por cierto, instruida por ésta, pero no en calidad de
} 
naturaleza, antropomorfizar lo real, volver todo al ámbito de lo ya conocido, instaurar el imperio de lo Mismo. ${ }^{22}$

[...] gracias solamente al hecho de que el hombre se olvida de sí mismo como sujeto y, por cierto, como sujeto artísticamente creador (künstlerisch schaffendes Subjekt), vive con cierta calma, seguridad y consecuencia; si pudiera salir, aunque solo fuese un instante, fuera de los muros de esa creencia que lo tiene prisionero, se terminaría en el acto su «conciencia de sí mismo (Selbstbewusstsein)».23

No hay una perspectiva privilegiada, ya que eso implicaría sostener una verdad objetiva, por lo que la imagen que construye el insecto o el pájaro no es menos ni más que la humana. Que un impulso nervioso, escindido de manera irreconciliable del objeto al que pretende remitir, esté asociado regularmente a determinada imagen tampoco es garantía de una causalidad, sino una costumbre al estilo de Hume. Si las leyes de la naturaleza se presentan de manera rigurosa ante nosotros, tiene razón Kant cuando afirma que las mismas proceden de nosotros. Nuestra tarea artística de producir metáforas debe obedecer a esa estructura humana, demasiado humana, pero entonces no tiene nada de sorprendente reconocer en la naturaleza eso que nosotros, de manera necesaria, introdujimos en ella. Y a partir de esta base metafórica se construye el edificio conceptual, el cual sigue preso de las relaciones de espacio, tiempo y número, necesarias para nosotros pero contingentes.

Y así llegamos a la segunda parte del ensayo nietzscheano, donde se señala la concordancia del lenguaje (Sprache) y la ciencia (Wissenschaft) como instancias continuas de construcción de conceptos. Labor semejante a la de las abejas, afirma Nietzsche en su convicción de la cercanía entre el hombre y el animal o, mejor dicho, el insecto. La ciencia como "necrópolis de las intuiciones (Begräbnisstätte der Anschauung) "24, sepulcro de esa antropomorfización de la escurridiza esencia de las cosas, estructura colosal que el intelecto busca rellenar no con presentes vivos, sino con esa otra muerte que implican los sentidos. Este edificio del conocimiento sirve de resguardo al indefenso investigador ante el choque de fuerzas (Mächte), encuentro de "verdades" distintas a la científica y que vienen a pujar por imponer su voluntad.

Lo propio del hombre no es el ya destronado impulso hacia la verdad, afirma Nietzsche, sino el impulso hacia la construcción de metáforas (Trieb zur Metapherbildung). Pero una vez erigido este mundo fijo y regular de leyes científicas, este impulso fundamental se encauza hacia otra tarea: el arte y la construcción de mitos. Es así como la vigilia se confunde con el sueño, cuando en el petrificado mundo del hombre despierto el espíritu creador del artista interrumpe las reglas, rompe la monotonía, abre el horizonte de lo posible anunciando ese porvenir imprevisible. Pascal y los antiguos griegos vienen a apoyar el ataque nietzscheano

un escolar que deja que el maestro le diga cuanto quiera, sino [en calidad] de un juez en ejercicio de su cargo, que obliga a los testigos a responder a las preguntas que él les plantea. Y así, incluso la física tiene que agradecer la tan provechosa revolución de su manera de pensar únicamente a la ocurrencia de buscar en la naturaleza (no atribuirle de manera infundada [anzudichten]), de acuerdo con lo que la razón misma introduce en ella, aquello que debe aprender de ella, de lo cual ella, por sí misma, no sabría nada.” Kant (2009), pp. 17-18.

22 Nietzsche (1980b), p. 883 [trad. Nietzsche (1996), p. 29].

23 Nietzsche (1980b), pp. 883-884 [trad. Nietzsche (1996), p. 29].

24 Nietzsche (1980b), p. 886 [trad. Nietzsche (1996), p. 33]. 
contra la vigilia cartesiana, cuando se contrapone el milagro continuo del mito a la dura mecánica causal tecno-científica. En este sentido, Nietzsche afirma que "el intelecto, ese maestro del fingir, se encuentra libre y relevado de su esclavitud habitual tanto tiempo como puede engañar sin causar daño". ${ }^{25}$ Nuevamente la afirmación de que el problema no pasa por el engaño, por la verdad o la mentira, sino por las consecuencias de cualquier enunciado que calificamos como negativas. Y ahora Nietzsche nos relata las andanzas de ese intelecto liberado de la servidumbre, espíritu creador soberano que inventa de manera incondicional, sin causa ni finalidad alguna. Al oponer Verstellung y Verzerrung ${ }^{26}$, fingimiento y distorsión, Nietzsche reivindica al primero por sobre el segundo. El artista finge, pero esto es una cosa buena y no moralmente condenada. Destruye y reconfigura el edificio conceptual de la ciencia, guiándose ahora ya por intuiciones singulares, individuales, desde ya que no "verdaderas". El camino desde estas hacia las abstracciones, "esquemas espectrales (gespentischen Schemata)"27, se vuelve intransitable. El espíritu creador se queda sin lenguaje, como el Funes de Borges, ya que al perder la capacidad de obedecer al imperio del concepto pierde también la palabra. ${ }^{28} \mathrm{O}$ tal vez alcanza una lengua prohibida (verbotenen) y nunca oída (unerhörten), apertura imposible hacia ese otro modo del lenguaje llamado escritura.

El texto termina contraponiendo al hombre racional y al hombre intuitivo, quienes en algunos períodos luchan por dominar la vida (das Leben zu herrschen). El primero se enfrenta a las necesidades con previsión (Vorsorge), prudencia (Klugheit) y regularidad (Regelmässigkeit), construyendo ese mundo rígido de leyes inquebrantables que hacen posible el cálculo y la aplicación mecánica de esas mismas normas. El otro danza sobre el abismo sin nada que ver o encontrar (begegnen) y tomando solo como real la vida disfrazada de apariencia (Schein) y belleza (Schönheit) ${ }^{29}$ El hombre guiado por conceptos busca conjurar la infelicidad (Unglück), el otro, a pesar de conjurar los males (Uebels), sufre. Es tan irracional (unvernünftig) en la desgracia (Leider) como en la felicidad (Glück), y en esto se opone a la apatía estoica, que gracias al uso de la razón comprende la necesidad de las cosas y se mantiene imperturbable ante el devenir del río de la vida.

No es difícil acertar dónde se encuentra Derrida dentro de esta escena. Y resulta válido señalar el paralelismo entre esas dos fuerzas vitales presentes en el texto nietzscheano con la contraposición que hace Rorty entre el modelo kantiano de hacer filosofía, donde el lenguaje encuentra un desarrollo normal que permite alcanzar objetivos comunes, y el modelo dialéctico, donde es necesario interrumpir la norma lingüística vigente para crear una nueva designación de las cosas. ${ }^{30}$ Desde ya que para este autor Derrida se encontraría en las filas de los dialécticos, quienes privilegian el momento literario o poético del lenguaje, artístico y creador, pero se convierten en parásitos que contaminan el andar perseverante de la norma kantiana, la cual "contribuye al levantamiento imparable y acompasador del edificio del conocimiento humano". ${ }^{31}$ También Habermas seguirá esta distinción entre un

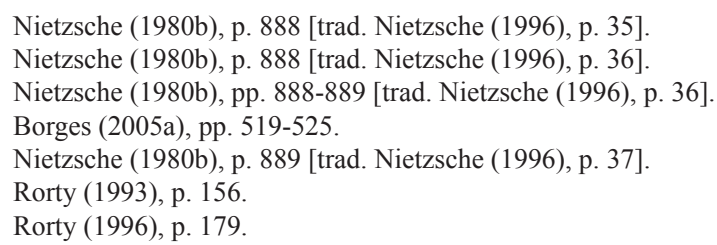


lenguaje con la capacidad de generar mundo y un lenguaje con la capacidad de resolver problemas. El primero crea conceptos para iluminar regiones del ser antes recluidas en las tinieblas y el segundo resulta productivo en su seriedad a la hora de resolver problemas..$^{32}$ Ambas perspectivas, las de Rorty y Habermas, encierran una crítica al hombre intuitivo, al filósofo artista, fundada en su inoperancia a la hora de enfrentarse al mundo de la vida cotidiana. Pero esta inutilidad, la de Nietzsche/ Derrida, ¿encierra otro modo de lo útil?

\section{Historia animal}

"Sobre la utilidad y el perjuicio de la historia para la vida" es el título de la Segunda consideración intempestiva de Nietzsche, escrita en 1874. Así como el primero de estos trabajos contra y fuera de su época está dedicado a David Strauss, el tercero a Schopenhauer y el cuarto a Wagner, en esta oportunidad el blanco del martillo nietzscheano será el historicismo. Esta corriente de pensamiento dominaba el espíritu alemán del siglo XIX gracias a la influencia de Niebuhr y Ranke, quienes consolidan una metodología que propone la búsqueda de objetividad histórica a partir del recurso a la fuente primaria, sumada a la pretensión de borrar la subjetividad del historiador de aquello que está reconstruyendo. ${ }^{33}$

El título y el comienzo de este escrito sentencian la lectura que hace Nietzsche de su época: "necesitamos la Historia para la vida y para la acción, no para apartarnos cómodamente de la vida y de la acción o para venerar la vida egoísta, la acción cobarde y malversada." ${ }^{34}$ ¿Por qué es intempestiva esta intervención? Porque el filósofo habla desde su sentimiento (Empfindung) y se opone a la hipertrofia de la instrucción histórica, fiebre que produce un daño en el pueblo. Entonces, Nietzsche se enfrenta al espíritu de su época, a su máximo orgullo: la cultura histórica. ¿Cómo lo hace? Oponiendo la vida y la acción a la objetividad y neutralidad historicistas, es decir, enfrentando otro modo de la historia a la historia como ciencia. $\mathrm{Y}$ en este campo de batalla varios conceptos tomarán su posición en los respectivos frentes. $\mathrm{La}$ decisión se contrapone a la aplicación mecánica de la norma, lo necesario aparece enfrentado a lo superfluo y la justicia combate contra el egoísmo. Pero nuevamente nos topamos con la cuestión sobre el criterio adoptado para privilegiar un enunciado por sobre otro. Y aquí Nietzsche explicita su respuesta: la vida, entendida como voluntad de poder, será lo que determine la preferencia por un discurso determinado.

Antes de llegar a este punto, el pensador alemán comienza señalando la envidia que siente el hombre hacia el animal, dichoso porque solo olvida, es decir, porque no tiene historia ni capacidad de fingir. El hombre habita en el presente asediado por el pasado, es un ser histórico que debe fingir. El hombre deja de ser el niño que juega en feliz ceguera entre el pasado y el futuro, el hombre encuentra en la existencia (Dasein) un "ininterrumpido haber sido, una cosa, que vive allí, de su propia negación y consumo, de su propia contradicción." 35 La felicidad de olvidar se opone al recuerdo absoluto, ya que la marca del pasado en todo instante lo vuelve

32 Habermas (1991), p. 248.

33 Para un riguroso análisis de la relación entre Nietzsche y la historiografía alemana del siglo XIX véase Brobjer (2007).

34 Nietzsche (1980a), p. 245 [trad. Nietzsche (2006), p. 10].

35 Nietzsche (1980a), p. 249 [la traducción es nuestra]. 
fugaz, perecedero, insignificante ante la inmensidad del paso del tiempo, peso que convierte al hombre en un camello cargado en exceso sobre sus espaldas. Nuevamente Funes, el memorioso, nos sale al encuentro, para recordarnos que estando condenado a ver en todo un devenir la única alternativa posible es el repliegue sobre sí en el más absoluto silencio, incapaz de salir de su oscuro cuarto, habiendo perdido la capacidad de actuar. Como el inmortal borgeano, que anclado a lo absoluto del tiempo permanece inmóvil e impasible ante la vida. ${ }^{36}$ Hay un exceso de vigilia en el sentido histórico de su época, sentencia Nietzsche, grado de insomnio tal que resulta perjudicial para la vida y que hunde (zu Grunde geht) a un individuo, un pueblo o una cultura. ${ }^{37}$ En otras palabras, el historicismo, con su pretensión de objetividad y absoluta transparencia historiográfica, arroja al suelo a quien lo adopta como perspectiva, lo conduce a lo profundo en su anhelo de fundamento (Grund). Y es por esta razón que, como bien analiza Cragnolini, Nietzsche opone la genealogía a la arqueología ${ }^{38}$, ya que no busca debajo de las capas que conforman la historia un origen, una verdad, un "presente vivo" que garantice la correspondencia de algún enunciado. El fundamento es el abismo (Abgrund), la ausencia de todo suelo, de profundidad, y es esta falta la que se traduce en olvido. Pero no en un olvido pasivo, como el del animal, sino en un olvido activo.

Para poder determinar ese grado y, con él, el límite a partir del cual lo pasado debe ser olvidado para no convertirse en el enterrador de lo presente (Todtengräber des Gegenwärtigen), sería necesario conocer la fuerza plástica (plastische Kraft) de cada humano, cada pueblo y cada cultura. Me refiero a aquella fuerza de crecer de sí mismo y de manera propia, de transformar (umzubilden) lo pasado y lo desconocido (Fremdes) y de incorporarlo, de sanar las heridas, recuperar lo perdido y recomponer (nachzuformen) desde sí mismo las formas quebradas. ${ }^{39}$

Es necesaria esa fuerza plástica que permite construir un horizonte (Horizont), es decir, un límite entre lo que se puede ver y aquello que escapa a nuestro alcance. Esta frontera, que separa el punto de vista histórico del ahistórico, no debe encerrarnos en una posición determinada, sino que sirve de condición de posibilidad para la apertura hacia lo otro. La acción implica un olvido, un desligarse del pasado, ya que una cadena causal inquebrantable impide toda decisión. Esta es la tesis de Nietzsche: lo histórico y lo ahistórico son ambos necesarios para la vida. ${ }^{40}$ No hay que optar entre el puro olvido animal o el historicismo. Debemos apropiarnos de los acontecimientos pasados desde esta fuerza plástica para así transformar lo sucedido (Geschehenen) en historia (Geschichte), reconociendo que ese gesto ahistórico implicará una injusticia (ungerechten) hacia aquello olvidado. Pero aquí reside a la vez la condición de posibilidad de la justicia (rechten), en tanto solo puede haber

36 Borges (2005a), pp. 519-525, 571-583.

37 Nietzsche (1980a), p. 250.

38 "Frente a una idea de arqueología, que tendería a buscar lo «verdadero» por debajo de las diversas capas de conceptos, valores, hábitos, la genealogía muestra las huellas, los trayectos, pero no encuentra tras los mismos una «verdad» que los justifique, sino juegos de fuerzas. Esos juegos de fuerzas son las interpretaciones." Cragnolini (2009), p. 148. Desde ya que esta perspectiva sigue la propuesta del clásico texto de Foucault (2008).

39 Nietzsche (1980a), p. 251 [trad. Nietzsche (2006), p. 17].

40 En este punto consideramos que es posible moderar la escisión que postula Brobjer (2004) entre la Segunda consideración intempestiva y los trabajos que Nietzsche realiza a partir de 1875-1876, a pesar del evidente rechazo que el comentarista encuentra en varios pasajes del corpus nietzscheano. 
decisión en el momento en que nos desligamos del peso de la historia re-construyendo una historia. El imposible recuerdo absoluto anula toda decisión, condición de posibilidad de la justicia. Como bien señala Derrida, si hay pura vigilia, solo nos queda obedecer de manera automática los mandatos de la historia, cuya eficacia causal nos volvería meros burócratas prisioneros de un programa ${ }^{41}$ Pero, al mismo tiempo, el olvido como condición de posibilidad de la justicia, en tanto interrupción del devenir histórico que nos conmina a asumir la responsabilidad de la decisión, siempre del otro, implica una injusticia hacia eso que dejamos en la oscuridad del pasado. Es por esto que la justicia, al encarnarse, se convierte en derecho, es decir, injusticia. Pero, no debemos olvidarnos, el derecho está asediado por la justicia, resto imposible de totalizar que vuelve perfectible infinitamente al derecho. ${ }^{42}$ Sin olvido no hay recuerdo posible, el olvido es la condición de posibilidad del recuerdo. Hay que olvidar, sí, pero para recordar eso que olvidamos.

Sin embargo, la propuesta de Nietzsche no se confunde con la visión suprahistórica, aquella que reconoce la atmósfera ahistórica que sirve de condición de posibilidad de los acontecimientos históricos y que nos permite comprender que pasado y presente se encuentran en un mismo nivel. En este sentido, esta perspectiva anula el devenir al sostener que ambas dimensiones temporales "esbozan un cuadro inmóvil de valor estable y de un significado siempre igual [stillstehendes Gebilde von unverändertem Werthe und ewig gleicher Bedeutung]." ${ }^{33}$ Perspectiva opuesta a la visión histórica, que considera al pasado como un peso que aprisiona al presente y que pone el acento en el proceso que permite deducir del primero tanto el presente como los sucesos futuros. Nietzsche se distanciará de ambas visiones, en cuanto persiguen un conocimiento, una sabiduría, obviando el criterio dado por la vida. Y para que no se confunda su posición con las anteriores, señalará dos hipótesis. En primer lugar, el conocimiento mata al fenómeno histórico, incluso cuando reconoce su fuerza, su potencia, su poder histórico [geschichtliche Macht], el cual quizá [vielleicht] prevalezca para el viviente. En segundo lugar, la historia como ciencia pura no debe ser soberana sino que tiene que subordinarse a una nueva y potente corriente vital [Lebensströmung] para así obedecer a un poder no-histórico. ${ }^{44}$ Entonces, la pregunta ahora consiste en saber hasta qué punto la vida necesita de la historia, reconociendo que un exceso implica un daño hacia lo viviente. La respuesta de Nietzsche parte de los tres aspectos que permiten pensar una pertenencia de la historia al ser vivo: en cuanto ser activo, en cuanto preserva y venera o en cuanto sufre y exige una liberación. A cada uno de estos tres corresponde una especie de historia: crítica, anticuaria y monumental.

Esta última, la historia monumental, se lanza en busca de modelos siguiendo la exigencia de que "lo grande sea eterno" 45 , es decir, circunscribiendo lo posible a aquella grandeza que fue ya una vez posible, clausurando la apertura a cualquier porvenir. Como afirma Derrida, cuando solo queda lo posible, el futuro se reduce

${ }^{41}$ Elegimos uno entre los múltiples lugares donde Derrida señala esta cuestión. "Sin el silencio, sin el hiato, que no es ausencia de reglas, sino necesidad de un salto en el momento de la decisión ética, jurídica o política, no tendríamos más que desarrollar el saber en un programa de acción. Nada sería más irresponsabilizante y más totalitario." Derrida (1997), p. 201. Todas las traducciones de Derrida son nuestras.

42 Derrida (1994a), pp. 50-51.

43 Nietzsche (1980a), p. 256 [trad. Nietzsche (2006), p. 25].

44 Nietzsche (1980a), p. 257 [trad. Nietzsche (2006), pp. 27-28].

45 Nietzsche (1980a), p. 259 [trad. Nietzsche (2006), p. 31]. 
a una extensión del presente ya capturado en su intempestividad. Si el porvenir es desbancado por lo posible, quedamos sujetos al cálculo, la previsión y la deducción mecánica de un presente futuro a partir de un programa preexistente. ${ }^{46}$ De esta manera, la singularidad irreductible del acontecimiento queda anulada, ya que la historia monumental

[...] siempre unificará, generalizará y equivaldrá (gleichsetzen) lo desigual (Ungleiche), siempre atenuará la heterogeneidad (Verschiedenheit) de los motivos y móviles para presentar, a costa de la causa, como ejemplar de ser imitado, su effectus monumental. Debido a su abstracción de las causas, la historia monumental podría describirse, con cierto grado de exageración, como una colección de "efectos en sí" o como una serie de acontecimientos (Ereignissen) que siempre surtirán los mismos efectos. ${ }^{47}$

Un acontecimiento previsible, anticipable, prefigurado y condenado a la eterna repetición de lo mismo ya no es tal. Para que los muertos triunfen sobre los vivos es necesario conceptualizar, es decir, olvidar la individualidad del pasado (Individualität des Vergangenen) y reducir las diferencias (Verschiedenen) bajo una forma general (allgemeine Form). ${ }^{48}$ El riesgo aquí inscripto consiste en no poder ya distinguir entre un pasado monumental y una ficción mística producto de la libre invención (freien Erdichtung $)^{49}$ al olvidar el olvido que opera en la mediación lingüística. En otras palabras, el problema no radica en la capacidad artística puesta en juego a la hora de desplegar una historiografía, sino en la negación de este artificio en manos de la pretendida verdad monumental.

Pero, como bien analiza Blanchot, si hay eterno retorno de lo mismo entonces no hay una presencia originaria que serviría de condena para el resto de los tiempos, ya que esa primera vez ya fue un retorno. ${ }^{50}$ ¿Qué significa esto? Que no hay un mismo que retorne, porque "nunca se produce algo absolutamente igual del juego de dados entre el futuro y el azar." ${ }^{51}$ En otras palabras, la concepción monumental de la historia cae en una contradicción en su anhelo de aniquilar la vida, ya que ese pasado vuelto una autoridad que eclipsa el presente no es más que el fruto de una interpretación sobre ese presente pasado que nunca fue tal y que no deja de reinventarse a cada momento.

En segundo lugar, la historia también pertenece a quien preserva y venera, volviéndose así historia anticuaria. En esta un individuo o un pueblo justifican su

46 "Pues un posible que sería solamente posible (no imposible), un posible seguramente y ciertamente posible, de entrada accesible, sería un mal posible, un posible sin porvenir, un posible ya dejado de lado, cabe decir, asegurado en la vida. Sería un programa o una causalidad, un desarrollo, un desplegarse sin acontecimiento.

La posibilitación de ese posible imposible debe restar a la vez tan indecidible y por lo tanto tan decisiva como el porvenir mismo." Derrida (1994b), p. 46.

47 Nietzsche (1980a), pp. 261-262 [trad. Nietzsche (2006), p. 35].

48 Nietzsche (1980a), p. 261 [trad. Nietzsche (2006), p. 34].

49 Nietzsche (1980a), p. 262 [trad. Nietzsche (2006), p. 36].

50 "La exigencia del retorno sería, pues, la exigencia de un tiempo sin presente, tiempo que sería también el de la escritura, tiempo futuro, tiempo pasado, que la radical disyunción (en ausencia de todo presente) de ambos, aunque fuesen los mismos, impide identificar de otro modo que no sea como la diferencia que la repetición sustenta. La mayor diferencia que se da entre pasado y futuro es que el uno repetiría al otro sin la común medida de un presente: como si entre pasado y futuro reinase la ausencia de presente bajo la forma simplificada del olvido. ¿Qué es lo que retornará? Todo, salvo el presente, la posibilidad de una presencia.” Blanchot (1994), p. 46.

51 Nietzsche (1980a), pp. 261-262 [la traducción es nuestra]. 
presente insertándose en la tradición que los acoge, felices de "no sentirse un mero capricho del azar y de la arbitrariedad (willkürlich und zufällig)". ${ }^{52}$ Pero esta relación con lo heredado implica una distorsión, fruto de la ausencia de una escala de valores (Werthverschiedenheiten) que permita establecer la justa proporción entre los fenómenos, asignándole así la misma importancia a objetos singulares heterogéneos. Al igual que en la historia monumental, el problema es la homogeneización, la igualación, la incapacidad para juzgar, criticar, seleccionar, es decir, crear una historia.

He aquí un peligro inmediato: al fin y al cabo, todo aquello que en esta visión (Gesichtskreis) es reconocido como añejo o propio del pasado simplemente recibe igual valoración, mientras que todo aquello que no demuestra el mismo respeto ante lo antiguo, es decir, todo lo nuevo y lo que está por nacer, se convierte en blanco del repudio y la enemistad. ${ }^{53}$

Nuevamente la historia, en este caso la anticuaria, se vuelve contra la vida, contra lo nuevo, contra el porvenir. Ambas historias hasta aquí presentadas devienen en una cancelación del futuro, un rechazo hacia todo aquello que excede el horizonte de lo posible y se anuncia como un imposible porvenir. La historia anticuaria sabe conservar la vida pero no crearla, carece de la capacidad artística que permite inventar lo inesperado. Por lo tanto, encadena al hombre de acción (Handelnden), quien siempre transgredirá toda piedad y veneración. ${ }^{54}$

Si bien los dos modos de la historia vistos hasta aquí son necesarios para la vida, deben articularse con el tercero: la historia crítica.

Para poder vivir, [la vida humana] ha de tener la fuerza, y de vez en cuando utilizarla, de quebrar y disolver una parte de su pasado: esto lo logra arrastrando ese pasado ante la justicia (Gericht), con el objetivo de inquirir minuciosamente en él y poder condenarlo firmemente. Todo pasado merece ser condenado, pues tal es la naturaleza de la condición humana: siempre han imperado en ella la violencia (Gewalt) y debilidad (Schwäche). No es la justicia la que ejerce su juicio aquí, ni mucho menos es la clemencia la que pronuncia el fallo: es la vida misma, esa potencia (Macht) oscura e impulsiva, insaciablemente anhelosa de sí misma. Su veredicto es siempre impiadoso, siempre injusto, porque nunca brota de la fuente pura del conocimiento (reinen Borne der Erkenntniss). ${ }^{55}$

La vida exige una potencia, un poder, que radica en la capacidad de abordar el pasado, someterlo a juicio y condenarlo. Pero esta perspectiva crítica lanzada contra la historia no obedece al saber, al conocimiento, a un conjunto de normas preestablecidas que prefiguran esa capacidad de juzgar. En este sentido, el juicio del artista o historiador crítico es siempre injusto, ya que excede el derecho vigente. Así, Nietzsche está diferenciando el derecho (elemento del cálculo) de la justicia (siempre incalculable), exigencias indisociables en su heterogeneidad. ${ }^{56} \mathrm{Y}$ si es necesaria una gran fuerza (Kraft) para vivir y olvidar que la vida es injusticia, a veces la vida

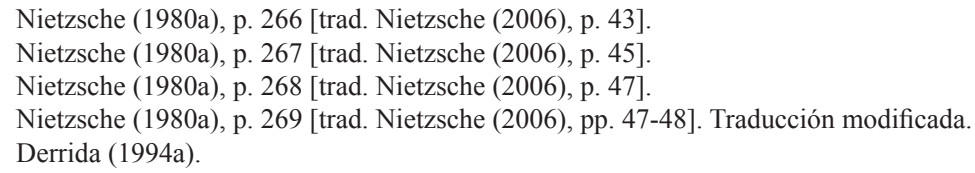


misma exige suspender temporalmente el olvido, es decir, olvidar el olvido. ${ }^{57}$

Este proceso es siempre peligroso (gefährlicher), especialmente peligroso para la vida misma, y los hombres y los tiempos que sirven de esta forma a ella, juzgando y aniquilando el pasado, son siempre hombres y tiempos peligrosos y a la vez en peligro. ${ }^{58}$

Los filósofos por venir, señala Derrida, son los pensadores del peligroso quizá ${ }^{59}$, quienes danzarán sobre el abismo, sobre la ausencia de sentido. En estos hombres, tan peligrosos como los tiempos que habitan, la contradicción no será superada ni suprimida, sino que reclamará "verdaderamente el pensamiento". ¿' ¿Por qué? Porque solo se da a pensar lo impensable, porque si su objeto fuera una totalidad cerrada sobre sí portadora de un sentido unívoco, la filosofía no sería más que análisis, desarrollo o explicitación de lo previamente afirmado, es decir, tendría como modelo un juicio analítico del tipo kantiano. Si hay síntesis es porque hay algo que no se deja sintetizar, que se resiste a ser puesto junto a otra cosa, una incompatibilidad o inconmensurabilidad irreductibles.

Los historiadores por venir están locos a los ojos de los metafísicos de todos los tiempos, que para Nietzsche somos nosotros también. Pero, a la vez, somos nosotros quienes aceptamos la locura como parte de la metafísica. Al plantearnos la cuestión de la aporía como fuente del pensamiento nos ubicamos en el umbral que augura un más allá de la tradición heredada. Soñar con ese pensamiento por venir es ya una locura, porque soñar es pensar. En otras palabras, la condición de posibilidad del anuncio de los filósofos del peligroso quizá es ese mismo pensamiento por venir, el cual es aquí encarnado por el historiador-artista crítico, quien olvidará ese olvido que hace posible la vida en un sentido pragmático, es decir, ese olvido que obtura el carácter injusto del pasado. Pero aquí debemos entender lo injusto como aquello fuera del derecho, anárquico en tanto infundado, contingente, irreductible a una norma, en otras palabras, lo injusto como condición de posibilidad de la justicia. ${ }^{61}$

La historia crítica sirve a la vida, entendida ahora como voluntad de poder ${ }^{62}$, cuando nos posibilita darnos a posteriori el pasado, construir una segunda naturaleza que se convertirá en primera naturaleza. ${ }^{63}$ No hay origen, no hay un pasado, no hay una verdad historiográfica, porque el ser es interpretación. Por lo tanto, es la vida la que debe dirigir nuestra relación con el pasado, y los tres tipos de historia pueden ser necesarios para esta labor. La clave radica en la orientación que se asuma, la cual no debe estar guiada por la búsqueda del saber, sino por el hambre, las necesidades

57 Derrida (1991), p. 30. Excede los límites de este trabajo incorporar aquí la cuestión del "don" como condición del olvido.

58 Nietzsche (1980a), p. 270 [trad. Nietzsche (2006), pp. 48-49]. Traducción modificada.

59 Nietzsche (1988a), pp. 16-17 [trad. Nietzsche (1997), pp. 23-24].

60 Derrida (1994b), p. 52.

61 La justicia, entendida como apertura incondicional ante la llegada de cualquier/absolutamente otro, requiere una puesta en suspenso del derecho, lo cual solo puede ser realizado gracias al carácter místico de su fundación. En otras palabras, el derecho está en constante auto-hetero-deconstrucción por estar construido sobre una violencia fundamental, anterior a la distinción entre justo e injusto (entendidos como legal e ilegal). Cf. Derrida (1994 ${ }^{\mathrm{a}}$ ), pp. 34-35.

62 La vida en sentido pragmático es derivada de la interpretación de la vida como voluntad de poder. "Algo vivo quiere, antes que nada, dar libre curso a su fuerza -la vida misma es voluntad de poder-: la autoconservación es tan solo una de las consecuencias indirectas y más frecuentes de esto.” Nietzsche (1988a), p. 27 [trad. Nietzsche (1997), pp. 36-37].

63 Nietzsche (1980a), p. 270 [trad. Nietzsche (2006), pp. 49-50]. 
y la fuerza plástica interna. ${ }^{64} \mathrm{Si}$ se adopta la perspectiva historicista permanecemos encerrados en la interioridad del hombre moderno a la espera de novedades "que reclaman ser conocidas para poder ser cuidadosamente encajadas". ${ }^{65}$ Ávidos de nuevas historias para archivar, nos sumergimos en la vorágine signada por el ritmo moderno: velocidad y novedad. En esa búsqueda de acrecentamiento constante quedamos presos de la técnica, reduciendo la tarea del historiador al mecánico despliegue de un programa establecido de antemano y obturando la artisticidad propia de la historia crítica, que también sería una potencial guía tanto de la historia monumental como de la historia anticuaria.

Expresándolo en términos morales: ya no lográis sostener lo sublime, vuestras hazañas, antes que truenos crujientes, son meras irrupciones del momento. Por más que llevéis a cabo las cosas más grandes y maravillosas, descenderán, a pesar de todo, sin canto ni gloria, al Orco. Porque el arte se da a la fuga en el instante en que cubrís vuestros actos con el tapiz de la Historia.

En un momento en que de uno se espera que se atenga, con perdurable entusiasmo, a lo incomprensible como expresión de lo sublime, toda aquel que intenta comprender (verstehen), calcular y acaparar (begreifen) puede ser calificado como sensato (verständig), pero solo en el sentido en que Schiller habla de la sensatez (Verstand) de los razonables (Verständigen): no ven ciertas cosas que hasta un niño ve, no oyen ciertas cosas que hasta un niño oye; estas cosas son, precisamente, las más importantes. [...] esa persona sensata ha destruido y perdido su instinto y no puede ya, confiando en el "divino animal" (göttlichen Thiere), soltar las riendas cuando su intelecto (Verstand) tambalea y su camino atraviesa desiertos. ${ }^{66}$

Es necesario algo del olvido animal para poder volverse historiador-artista, es decir, es necesario interpretar el pasado, gesto creador por excelencia, y rechazar un acceso conceptual a lo histórico en sí mismo. Cuando la razón monopoliza nuestra relación con el pasado nos volvemos inmunes a lo incomprensible, no podemos acoger ese espectro que asedia nuestra historia y, por lo tanto, nuestro aquí y ahora. Desde esta perspectiva, la filosofía resulta inerte, inoperante e inútil, desde que tiene permitido un máximo despliegue en el ámbito de la interioridad "pero llevado al plano del mundo de la acción (Handeln), de aquello que denominamos vida real (Leben), ya no parece ser así: aquí solo se permite una sola cosa y se declara imposible todo lo demás. ${ }^{\circ 67}$ ¿Por qué el historicismo es inútil para la vida? Porque nos condena a lo posible, que en términos derrideanos siempre es un horizonte de espera determinado por un presente. Y en este sentido, lo posible es histórico, contingente, limitado y frágil, volviéndose lo imposible realizable en tanto que escapa a los límites que se trazan desde la interioridad del sujeto moderno. Y aquí nos encontramos con otra de las tesis nietzscheanas: solo los fuertes (starken), las fuerzas activas, pueden asumir esta otra perspectiva sobre la historia, las fuerzas débiles (schwachen) o reactivas serán arrasadas por esta. ${ }^{68}$ Pero esta potencia, que tiene la fuerza suficiente para rechazar la objetividad, no renuncia a la verdad para caer presa del relativismo propio

64 Nietzsche (1980a), p. 272 [trad. Nietzsche (2006), p. 53].

65 Nietzsche (1980a), p. 274 [trad. Nietzsche (2006), p. 56].

${ }_{66}$ Nietzsche (1980a), p. 280 [trad. Nietzsche (2006), p. 66].

${ }_{67}$ Nietzsche (1980a), p. 282 [trad. Nietzsche (2006), p. 70].

68 Nietzsche (1980a), p. 283 [trad. Nietzsche (2006), p. 71]. 
del nihilismo absoluto ${ }^{69}$, que podría conducir a lecturas revisionistas o negacionistas de la historia, sino todo lo contrario.

Es que él añora la verdad, pero no como una fría e inefectiva iluminación, sino, antes bien, como jueza (Richterin) que ordena y castiga; no anhela la verdad como posesión egoísta del individuo, sino como justificación sagrada que le permita ensanchar las delimitaciones de las posesiones egoístas. En una palabra, quiere la verdad a modo del juicio universal (Weltgericht) y no como la presa capturada y el placer del cazador individual. Solo en cuanto el hombre verídico tiene la voluntad incondicional (unbedingten Willen) de ser justo (gerecht), existe algo grande en esa búsqueda de la verdad. ${ }^{70}$

La propuesta nietzscheana consistirá en asumir a la objetividad no como aquella dinámica que permitiría a una impresión grabarse en la tabula rasa del pasivo historiador, sino como una creación en manos del artista, quien configura una narración a partir de los acontecimientos. Por lo tanto, "objetivo" y "verdadero" no son conceptos asociados, ya que muchas veces el primero implica un interpretar creador que asume su carácter ficcional, obra cumbre del filósofo-artista por venir. ${ }^{71}$ ¿Qué más objetivo que configurar una lectura posible de nuestro pasado explicitando que esta no es más que una entre múltiples posibles narrativas? Pero entonces, ¿por qué privilegiaríamos esta interpretación por sobre las demás? Por su utilidad para la vida, es decir, porque obedece a una fuerza activa que busca incrementar, sin acumulación ni concentración, la voluntad de poder, la multiplicidad de fuerzas que atraviesan y configuran lo real. Solo los "arquitectos del futuro (Baumeister der Zukunft) y conocedores del presente (Wissende der Gegenwart)" 72 podrán acceder a la voz del pasado para abrir a la llegada del porvenir, esa alteridad irreductible que no puede anticiparse ni reducirse a un presente futuro determinado. Condenar el futuro a lo posible es aniquilar la vida, movimiento que caracteriza a la concepción cristianoteológica que nos sentencia a un próximo fin del mundo. ${ }^{73}$ Desde esta perspectiva, no hay alternativa posible, no hay invención posible y eso que llamamos mundo no es más que una eterna repetición de este mismo mundo presente. Esta condena, para Nietzsche, no hace más que explicitar el carácter teológico de la historia, por lo tanto, su naturaleza histórica. Entonces, debemos reconocer que la lenta cancelación del futuro no es más que un efecto histórico y permitir que el conocimiento vuelva su aguijón contra sí mismo. ${ }^{74}$ Movimiento característico de la deconstrucción, gesto hipercrítico que retorna sobre sí, sobre la herencia inscripta en la noción misma de "crítica". En otras palabras, debemos estar en guerra contra nosotros mismos. ${ }^{75}$

\footnotetext{
Para los tipos de nihilismo en Nietzsche véase Cragnolini (2010).

Nietzsche (1980a), p. 287 [trad. Nietzsche (2006), p. 77].

Nietzsche (1980a), p. 289-293 [trad. Nietzsche (2006), pp. 82-87].

Nietzsche (1980a), p. 294 [trad. Nietzsche (2006), p. 91].

Nietzsche (1980a), p. 304 [trad. Nietzsche (2006), p. 106].

Nietzsche (1980a), p. 306 [trad. Nietzsche (2006), p. 110].

"Estoy en guerra contra mí mismo", título de la última entrevista que diera Derrida en vida para Le Monde el 19 de Agosto de 2004, luego publicada en forma de libro en Derrida (2005).
} 


\section{Deconstrucción animal}

El pensamiento de la deconstrucción, que asedia desde un futuro pasado a la filosofía del martillo nietzscheana, puede abordarse a partir de dos principios fundamentales. El primero declara la imposibilidad del "uno", es decir, la diseminación finita pero incontable detrás de toda marca. Gesto que no debe confundirse con un relativismo nihilista sino todo lo contrario, al reconocer el carácter ficcional de toda perspectiva y la necesidad de mantener una vigilancia constante sobre todos aquellos fundamentos que pretendan fundar un origen. No hay un sentido unívoco detrás del significante, no hay un presente vivo al que corresponda una intuición primigenia, no hay una arkhé sobre la que fundar un dogma. En palabras de Zaratustra:

Los viejos dioses hace ya mucho tiempo, en efecto, que se acabaron: - iy en verdad, tuvieron un buen y alegre final de dioses!

No encontraron la muerte en un «crepúsculo», - ; esa es la mentira que se dice! Antes bien, encontraron su propia muerte - ¡riéndose (gelacht)!

Esto ocurrió cuando la palabra más atea (gottloseste) de todas fue pronunciada por un dios mismo, -la palabra: «¡Existe un único dios! ¡No tendrás otros dioses junto a mí!»-un viejo dios huraño, un dios celoso se sobrepasó de este modo:

$\mathrm{Y}$ todos los dioses rieron entonces, se bambolearon en sus asientos y gritaron: «¿No consiste la divinidad precisamente en que existan dioses, pero no dios?»

El que tenga oídos, oiga. ${ }^{76}$

La muerte de Dios es la consecuencia necesaria del deber de veracidad que guía al cristianismo, por eso es un Dios quien declara la muerte de Dios. ${ }^{77}$ Pero a pesar de su defunción, la sombra divina continúa asediando bajo otras figuras de lo uno. $^{78}$ Entre estas, Nietzsche afirma que Dios está inscripto en el lenguaje, por lo tanto, "no vamos a desembarazarnos de Dios porque continuamos creyendo en la gramática." ${ }^{79}$ Así llegamos al segundo principio de la deconstrucción, según el cual no hay un más allá, sino que el más allá está dentro. Aporía inscripta en toda herencia, la cual implica siempre una tarea: el deber de traicionar el legado. Porque no hay una herencia, pero a la vez no hay un más allá de la misma, sino que esa exterioridad, la posibilidad de la invención, es parte de la tradición en la cual nos inscribimos. ${ }^{80}$ Es por esta razón que Nietzsche, el intempestivo, busca actuar contra (gegen) y sobre (dadurch auf) el tiempo pero a favor de un tiempo por venir (zu Gunsten einer kommenden Zeit). ${ }^{81}$ Esquema que resume de manera ejemplar el gesto que implica la deconstrucción. Contra la totalidad a la que se enfrenta, en este caso nuestro tiempo, pero dentro de ella, transitando ese resto que impide el cierre de la mismidad sobre sí, señalando el imposible porvenir que la asedia. ${ }^{82}$ Por lo tanto, los

76 Nietzsche (1988b), p. 230 [trad. Nietzsche (1998a), p. 260].

77 Cf. Nancy (2008).

78 "Dios ha muerto: sin embargo, tal como es la especie humana, durante milenios habrá cavernas en las que tal vez se mostrará su sombra. Y nosotros - ¡también nosotros tenemos que vencer todavía su sombra!" Nietzsche (1988c), p. 467 [trad. Nietzsche (1999), p. 105].

79 Nietzsche (1988d), p. 78 [trad. Nietzsche (1998b), p. 55].

80 "La herencia no es nunca algo dado (donné), es una tarea." Derrida (1993), p. 94.

${ }_{81}$ Nietzsche (1980a), p. 247 [trad. Nietzsche (2006), p. 12].

82 "Teniendo en cuenta estos efectos de sistema, no se tiene, desde adentro donde «nosotros somos (sommes)», más que la elección entre dos estrategias: 
filósofos de un tipo nuevo, los filósofos por venir que anuncia Nietzsche, siguen inmersos en la tradición monotonoteista. Pero como esta herencia no es una, allí reside lo imposible por venir. ¿Cuál es la tarea que nos lega Nietzsche? "Seguir sin seguir." ${ }^{83}$ Y Derrida se convierte así en uno de esos filósofos del porvenir anunciados por Nietzsche, que desde un futuro anterior abre a la posibilidad de su llegada. Y esta apertura es, a la vez, una puesta en crisis de las fronteras sobre las que se construye la tradición que nos atraviesa. Porque ya no podemos distinguir con claridad y distinción dónde comienza y dónde termina el territorio gobernado por esas unidades conceptuales asediadas por lo otro de sí. Entre estos límites en ruinas, Nietzsche/ Derrida privilegiarán aquel que separa al hombre del animal, frente sobre el que se construyó la metafísica occidental y que tanto la figura del ultrahombre como la del animot vienen a hacer temblar desde su interior.

\section{Referencias bibliográficas}

Blanchot, M. (1970): El diálogo inconcluso, trad. P. de Place, Caracas, Monte Ávila. Blanchot, M. (1994): El paso (no) más allá, trad. C. de Peretti, Barcelona, Paidós.

Borges, J. L. (2005a): Obras completas I, Bs. As., Emecé.

Borges, J. L. (2005b): Obras completas II, Bs. As., Emecé.

Brobjer, T. (2004): "Nietzsche's View of the Value of Historical Studies and Methods", Journal of the History of Ideas, 65, pp. 301-322.

Brobjer, T. (2007): "Nietzsche's Relation to Historical Methods and Nineteenth-Century German Historiography”, History and Theory, 46, pp. 155-179.

Cragnolini, M. (2009): "El lugar de la historia en el pensamiento de Nietzsche", en D. Brauer (ed.), La historia desde la filosofía. Volumen 2, Bs. As., Prometeo, pp. 139-153.

Cragnolini, M. (2010): “Albergando el desierto: Nietzsche y la cuestión de la nada”, Estudios Nietzsche, 1/1, pp. 181-198.

Cragnolini, M. (2016): Extraños animales, Bs. As., Prometeo.

Derrida, J. (1972a): "Signature, événement, contexte", en Marges de la Philosophie, Paris, Minuit, pp. 365-393.

Derrida, J. (1972b): "Les fins de l'homme”, en Marges de la Philosophie, Paris, Minuit, pp. 129-164.

Derrida, J. (1972c): “La mythologie blanche”, en Marges de la Philosophie, Paris, Minuit, pp. 247-324.

1) Intentar la salida y la deconstrucción sin cambiar de terreno, repitiendo lo implícito de los conceptos fundadores y de la problemática original, utilizando contra el edificio los instrumentos o las piedras disponibles en la casa, es decir también en la lengua. El riesgo aquí es confirmar, consolidar o relevar (relever) sin cesar en una profundidad siempre más segura aquello mismo que se pretende deconstruir. La explicitación continua hacia la apertura corre el riesgo de hundirse en el autismo del cierre.

2) Decidir cambiar de terreno, de manera discontinua e irruptiva, instalándose brutalmente fuera y afirmando la ruptura y la diferencia absolutas. Sin hablar de todas las otras formas de perspectivas de apariencia engañosa (en trompe-l'oeil) que pueden acunar un tal desplazamiento, habitando más ingenuamente, más estrechamente que nunca el adentro que se declara desertar, la simple práctica de la lengua reinstala sin cesar el «nuevo» terreno sobre el más viejo suelo. Se podría mostrar sobre ejemplos numerosos y precisos los efectos de una reinstalación tal o de una ceguera como esa.

Va de suyo que estos efectos no son suficientes para anular la necesidad de un «cambio de terreno». Va de suyo también que entre estas dos formas de deconstrucción la elección no puede ser simple y única. Una nueva escritura debe tejer y entrelazar los dos motivos.” Derrida (19721b), pp. 162-163.

83 Derrida (1994b), p. 51. 
Derrida, J. (1991): Donner le temps, 1. La fausse monnaie, Paris, Galilée.

Derrida, J. (1993): Spectres de Marx. L'état de la dette, le travail du deuil et la nouvelle Internationale, Paris, Galilée.

Derrida, J. (1994a): Force de loi, Paris, Galilée.

Derrida, J. (1994b): Politiques de l'amitié, suivi de L'oreille de Heidegger, Paris, Galilée.

Derrida, J. (1997): "Le mot d'accueil”, en Adieu à Emmanuel Lévinas, Paris, Galilée.

Derrida, J. (2005): Apprendre à vivre enfin. Entretien avec Jean Birnbaum, Paris, Galilée.

Foucault, M. (2008): Nietzsche, la genealogía, la historia, trad. J. Vázquez Pérez, Valencia, Pre-textos.

Habermas, J. (1991): El discurso filosófico de la modernidad (doce lecciones), trad. M. Jiménez Redondo, Madrid, Taurus.

Kant, I. (1995): Fundamentación de la metafísica de las costumbres, trad. M. G. Morente, México, Porrúa.

Kant, I. (2009): Crítica de la razón pura, trad. M. Caimi, México, FCE.

Nancy, J.-L. (2008): La declosión: (Deconstrucción del cristianismo, 1), Bs. As., La cebra.

Nietzsche, F. (1980a): "Unzeitgemäße Betrachtungen II", Sämtliche Werke. Kritische Studienausgabe in 15 Bänden, 1, Hrsg. von Giorgio Colli und Mazzino Montinari, München, Berlin/New York, Deutscher Taschenbuch Verlag und Walter de Gruyter, pp. 243-334.

Nietzsche, F. (1980b): “Ueber Wahrheit und Lüge im aussermoralischen Sinne”, Sämtliche Werke. Kritische Studienausgabe in 15 Bänden, 1, Hrsg. von Giorgio Colli und Mazzino Montinari, München, Berlin/New York, Deutscher Taschenbuch Verlag und Walter de Gruyter, pp. 873-890.

Nietzsche, F. (1980c): “Die Geburt der Tragödie”, Sämtliche Werke. Kritische Studienausgabe in 15 Bänden, 1, Hrsg. von Giorgio Colli und Mazzino Montinari, München, Berlin/New York, Deutscher Taschenbuch Verlag und Walter de Gruyter, pp. 9-156.

Nietzsche, F. (1980d): "Ecce homo", Sämtliche Werke. Kritische Studienausgabe in 15 Bänden, 6, Hrsg. von Giorgio Colli und Mazzino Montinari, München, Berlin/New York, Deutscher Taschenbuch Verlag und Walter de Gruyter, pp. 255-374.

Nietzsche, F.(1988a): “Jenseits von Gut und Böse”, Sämtliche Werke. Kritische Studienausgabe in 15 Bänden, 5, Hrsg. von Giorgio Colli und Mazzino Montinari, München, Berlin/New York, Deutscher Taschenbuch Verlag und Walter de Gruyter, pp. 9-244.

Nietzsche, F. (1988b): "Also sprach Zarathustra I-IV", Sämtliche Werke. Kritische Studienausgabe in 15 Bänden, 4, Hrsg. von Giorgio Colli und Mazzino Montinari, München, Berlin/New York, Deutscher Taschenbuch Verlag und Walter de Gruyter.

Nietzsche, F. (1988c): "Die fröhliche Wissenschaft", Sämtliche Werke. Kritische Studienausgabe in 15 Bänden, 3, Hrsg. von Giorgio Colli und Mazzino Montinari, München, Berlin/New York, Deutscher Taschenbuch Verlag und Walter de Gruyter, pp. 343-652.

Nietzsche, F. (1988d): “Götzen-Dämmerung”, Sämtliche Werke. Kritische Studienausgabe in 15 Bänden, 6, Hrsg. von Giorgio Colli und Mazzino Montinari, München, Berlin/New York, Deutscher Taschenbuch Verlag und Walter de Gruyter, pp. 55-162.

Nietzsche, F. (1996): Sobre verdad y mentira en sentido extramoral, trad. L. Valdés, Madrid, Tecnos.

Nietzsche, F. (1997): Más allá del bien y del mal, trad. A. Sánchez Pascual, Madrid, Alianza. Nietzsche, F. (1998a): Así habló Zaratustra, trad. A. Sánchez Pascual, Madrid, Alianza.

Nietzsche, F. (1998b): Crepúsculo de los ídolos, trad. A. Sánchez Pascual, Madrid, Alianza. Nietzsche, F. (1999): La ciencia jovial, trad. J. Jara, Caracas, Monte Ávila. 
Nietzsche, F (2000): El nacimiento de la tragedia, trad. A. Sánchez Pascual, Madrid, Alianza. Nietzsche, F (2006): Segunda consideración intempestiva. Sobre la utilidad y los inconvenientes de la Historia para la vida, trad. J. Etorena, Bs. As., Libros del Zorzal.

Rorty, R. (1993): Ensayos sobre Heidegger y otros pensadores contemporáneos. Escritos filosóficos 2, trad. J. Rubio, Barcelona, Paidós.

Rorty, R. (1996): Consecuencias del pragmatismo, trad. J. M. Cloquell, Madrid, Tecnos.

Santiago Guervós, L. (2000): "El poder de la palabra: Nietzsche y la retórica”, en F. Nietzsche, Escritos de retórica, ed. y trad. L. Santiago Guervós, Madrid, Trotta, pp. 9-77. 